\title{
Olfactory and behavioral response thresholds to odors of diseased brood differ between hygienic and non-hygienic honey bees (Apis mellifera L.)
}

Accepted: 25 May 2001 / Published online: 11 July 2001

(C) Springer-Verlag 2001

\begin{abstract}
Through the use of proboscis-extension reflex conditioning, we demonstrate that honey bees (Apis mellifera L.) bred for hygienic behavior (a behavioral mechanism of disease resistance) are able to discriminate between odors of healthy and diseased brood at a lower stimulus level than bees from a non-hygienic line. Electroantennogram recordings confirmed that hygienic bees exhibit increased olfactory sensitivity to low concentrations of the odor of chalkbrood infected pupae (a fungal disease caused by Ascosphaera apis). Three-week-old hygienic bees were able to discriminate between the brood odors significantly better than three-week old non-hygienic bees. However, the differential performance in brood odor discrimination was primarily genetically based, not a direct result of age, experience, or the temporary behavioral state of the bee. Lower stimulus thresholds for both the olfactory and behavioral responses of hygienic bees may facilitate their ability to detect, uncap and remove diseased brood rapidly from the nest. In contrast, non-hygienic bees, possessing higher response thresholds, may not be able to detect diseased brood as easily. Our results provide an example of how physiological and behavioral differences between the hygienic and non-hygienic honey bee lines, operating at the level of the individual, could produce colonyspecific behavioral phenotypes.
\end{abstract}

Keywords Apis mellifera $\cdot$ Response thresholds · Proboscis-extension reflex · Hygienic behavior . Electroantennogram

R. Masterman $\cdot$ R. Ross $\cdot$ K. Mesce $\cdot$ M. Spivak $(\bowtie)$

Department of Entomology, University of Minnesota,

219 Hodson Hall, 1980 Folwell Avenue, Saint Paul,

MN 55108, USA

E-mail: spiva001@tc.umn.edu

Tel.: + 1-612-6244798

Fax: + 1-612-6255299

K. Mesce

Graduate Program in Neuroscience,

University of Minnesota, 219 Hodson Hall,

1980 Folwell Avenue, Saint Paul, MN 55108, USA
Abbreviations $C B E$ : chalkbrood equivalent $C S$ : conditioned stimulus $\cdot D I$ : discrimination index $\cdot E A G$ : electroantennogram $\cdot P E R$ : proboscis extension reflex $\cdot T P E$ : total proboscis extension $\cdot U S$ : unconditioned stimulus

\section{Introduction}

A honeybee colony is composed primarily of workers that perform a wide range of behavioral tasks (Seeley 1985; Winston 1987). As worker bees age, there is a relatively consistent transition from in-hive tasks (brood care and cell cleaning) to tasks performed outside the nest (foraging) (Seeley and Kolmes 1991). Individual bees of a similar age, however, can display a remarkable plasticity in their behavioral repertoires (Page and Robinson 1991; Robinson 1992; van der Blom 1993). Behavioral variability in temporal task performance and specialization stems from a high degree of genetic variation among individuals, and is influenced by the colony environment and its needs (Calderone and Page 1988, 1991, 1992).

Recent ideas presented to explain task allocation have been based on a response threshold model, in which the tendency to perform certain tasks is mediated by an individual's response threshold to stimuli that elicit a specific behavior (Calderone and Page 1988; Page and Mitchell 1991; Robinson 1992; Page 1997; Theraulaz et al. 1998; Arathi and Spivak 2001). Assuming an individual has the capacity to detect a particular stimulus, the insect should respond when the stimulus intensity exceeds its threshold. Response thresholds are determined by an individual's genetics, behavioral state, age, and by other external factors such as colony resources, climate, and interactions with colony members (Page and Mitchell 1991; Page and Robinson 1991; Page 1997; Theraulaz et al. 1998). Thus, complex patterns of temporal task performance and specialization may arise within a social environment because individuals possess varying stimulus detection and behavioral 
response thresholds. In this study, we examined whether response thresholds could play a role in the expression of hygienic behavior.

An economically important behavior in honey bees, hygienic behavior, has been well studied at the colony level, but not at the level of the individual bee (reviewed in Spivak and Gilliam 1998a, 1998b). Bees that perform hygienic behavior are able to detect, uncap, and remove diseased brood from the nest before the pathogen sporulates and becomes infectious (Woodrow and Holst 1942; Rothenbuhler 1964; Gilliam et al. 1983). Bees also detect, uncap and remove brood parasitized by the mite, Varroa destructor (Anderson and Trueman 2000), interrupting the reproductive cycle of the mite (Peng et al. 1987; Boecking and Drescher 1991, 1992; Spivak 1996). Thus, hygienic behavior is one mechanism of resistance to brood disease and $V$. destructor mites (Spivak and Reuter 1998, 2001). The behavior is thought to be governed by two recessive loci, one for uncapping the wax covered cell containing a diseased larva or pupa, and one for removing the diseased brood from the nest (Rothenbuhler 1964).

Here we tested whether the ability of individual hygienic and non-hygienic bees to discriminate healthy from diseased brood increased with age, and whether the bees' detection and behavioral responses to the brood odors were elicited at different stimulus thresholds. Our underlying hypothesis is that hygienic bees may have an enhanced ability to detect abnormal brood odors, thus making them more likely to initiate uncapping and brood removal behaviors.

In a previous study, we utilized proboscis extension reflex (PER) conditioning to reveal differences in the abilities of bees from hygienic and non-hygienic colonies to discriminate between odors of healthy and diseased pupae and pupae infected with chalkbrood, a fungal disease caused by Ascosphaera apis (Masterman et al. 2000). Although both genetic lines showed a similar performance in discriminating between easily conditioned, highly concentrated, floral odors (geraniol and 1-hexanol), bees from the hygienic line, which were collected while in the act of performing hygienic behavior (uncapping or removing dead brood), were better able to discriminate between healthy and diseased brood odors than bees from the non-hygienic colony.

In the first experiments of our present study, hereafter called the Age study, we used PER conditioning to test whether the ability to discriminate between the brood odors increased with age, and whether these differences were based on genotype or were a result of a transient behavioral state of the hygienic bees when collected from the colony. In the second set of experiments, hereafter called the Threshold study, we determined if there were threshold level differences between the two lines of bees for the detection and behavioral response to brood odors. Our first objective in the Threshold study was to evaluate the ability of individual bees from hygienic and non-hygienic colonies to dis- criminate between odors of healthy and diseased pupae, at different stimulus levels, using PER conditioning. The second objective of the Threshold study was to determine whether hygienic bees displayed increased olfactory sensitivity to brood odors when compared to the olfactory response of non-hygienic bees. We used electroantennogram (EAG) recording to assay these chemosensory differences. EAGs have been previously used to determine olfactory stimulus-sensitivities to a wide variety of odorants in the honey bee (e.g., Williams et al. 1982; Patte et al. 1989) and to study the effects of olfactory conditioning on receptor sensitivities in worker bees (De Jong and Pham-Delegue 1991). EAG and PER conditioning assays have been used in combination to study learning in the honey bee and stimulus-intensity dynamics during olfactory processing (Bhagavan and Smith 1997). However, our EAG study is the first to examine genetic differences among worker bees and how the detection of behaviorally significant olfactory cues, emanating from diseased pupae, may differ among the bee lines.

Determining whether there are differences between hygienic and non-hygienic bees in their olfactory sensitivity (using EAG recordings) and behavioral response thresholds (using PER conditioning) will facilitate our understanding of the neural mechanisms underlying this complex and economically important behavior. In addition, these studies provide insights into how complex colony-level behaviors can arise from the behavioral plasticity of individual bees.

\section{Materials and methods}

\section{Breeding}

The breeding program for hygienic behavior was initiated in 1993 by selecting colonies of Italian-derived, A. mellifera bees using a freeze-killed brood assay described in Spivak and Downey (1998). Colonies that uncapped and removed freeze-killed brood within $48 \mathrm{~h}$ were considered hygienic; those that took over 6 days to perform the same task were considered non-hygienic. To establish and maintain the lines, queen bees were raised from colonies that displayed the most rapid and least rapid removal rates. For each generation, the daughter hygienic queens were instrumentally inseminated with a mixture of semen from drones from different hygienic colonies. Similarly, daughters from the most non-hygienic queens were inseminated with sperm of drones from the most non-hygienic colonies.

\section{Proboscis-extension conditioning methods}

The PER conditioning experiments were conducted in 1997 and 1998. In 1997, one hygienic and one non-hygienic colony were chosen from the 4th generation of selected colonies to be the source of bees (parental colonies) for the experiments that year. In 1998, one hygienic and non-hygienic colony were chosen from the 5th generation, and were derived from different sublines (queen lines) than the colonies in 1997. The parental colonies were maintained in standard Langstroth equipment. The criteria for selection of these colonies were based on their relative rates of removal of freezekilled brood, and otherwise were similar in populations and nectar and pollen reserves. 
For the experiments, immature bees (larvae and pupae) from hygienic and non-hygienic colonies were raised together by one nursery colony. Frames of eggs from the parent hygienic and nonhygienic colony were moved into a nursery colony that was headed by a naturally mated queen. The frames with introduced eggs were placed above a queen excluder, a device which prevented the queen in the nursery colony from laying her own eggs in the introduced combs. The use of the nursery colony eliminated potential effects that could be a result of nutritional differences in colony brood rearing. Combs containing pupae within one to two days of eclosion were removed from the nursery colony and placed in individual cages in an incubator held at $34^{\circ} \mathrm{C}$ and $50 \%$ relative humidity. The eclosing bees were marked with paint or a colored and numbered tag to identify them by age, and were then introduced into observation hives.

The observation hives were set up three days prior to the addition of marked bees. Each observation hive was provided with a frame of nectar and pollen, and a frame of larvae. Approximately 1,000 unmarked bees of various ages from a hygienic colony were added to the observation hives initially to maintain a normal age structure in the colony and each observation hive was provided with a naturally mated queen. The observation hive colonies were allowed to rear brood from the queen, but the brood was not allowed to eclose. Instead, frames of brood were moved out of the observation hives approximately every 2 weeks and replaced with a frame of young brood. In this way, the only adult bees in the colony were the original unmarked bees, and the newly added marked bees.

Marked bees were added to the observation hives to create "mixed-line" or "single-line" colonies. In 1997, 75 marked hygienic bees and 25 marked non-hygienic bees were added to one observation hive every 3 days for approximately 4 weeks to create a mixed-line composition colony. This colony was used in the first set of trials for the Threshold study. The trials began 3 weeks after the first marked bees were added to the observation hive, when the oldest unmarked bees were 24 days, and the oldest hygienic and non-hygienic bees were 21 days old. In 1998, a mixed-line and two single-line colonies (one hygienic and one non-hygienic) were created, all from the same parental hygienic and non-hygienic colonies. The colonies were established as in 1997 but a total of 140 marked bees (either hygienic, nonhygienic or a combination of the two lines) were added every 3 days for 8 weeks for a total of approximately 2,600 marked bees for each colony. In addition, similar proportions of unmarked bees were added to maintain a sufficient population of bees in the hive. More bees were added in 1998 because these colonies were used both for the Age study and a replication of the Threshold study. The experiments began 4 weeks after the first marked bees were added to the observation hive, when the oldest marked hygienic and non-hygienic bees were 28 days old.

For the Age study, bees were collected prior to the addition of the freeze-killed brood stimulus that triggers hygienic behavior. In this way, no bees were collected while performing hygienic behavior. We collected bees of 1 week and 3 weeks of age to determine if there were age based differences in their discrimination abilities. Bees of the correct age were carefully removed from the observation hives by placing a wire screen cage over them and allowing them to walk up the side of the cage.

In the Threshold study, a freeze-killed brood comb section was inserted into the observation hives to elicit the hygienic response $2 \mathrm{~h}$ before bees were collected for the learning trials. In 1998, the freeze-killed brood was placed in the colonies only after the Age study was completed. Bees from the hygienic line observed to uncap or remove the freeze-killed brood were collected by placing a wire screen over them and allowing them to walk into the cage. Same age marked bees from the non-hygienic line, although not observed removing dead brood, were collected at the same time from the freeze-killed brood insert. Non-hygienic bees do perform hygienic behavior, although rarely (Arathi et al. 2000); thus it was not possible to collect sufficient non-hygienic bees performing the behavior for the experiments.

\section{PER discrimination conditioning}

After collection from the observations hives, bees for all PER experiments were directly transferred to the laboratory where they were cooled on ice until they became inactive. Immediately after cooling, bees were harnessed in a restraining apparatus (Menzel and Bitterman 1983). Restrained bees were able to move their antennae and proboscises freely. Fifteen minutes after the bees were harnessed, they were fed $0.4 \mu \mathrm{l}$ of $2 \mathrm{~mol}^{-1}$ sucrose solution. The conditioning trials began two hours after they were harnessed and fed.

For the conditioning trials, bees were positioned in an open Plexiglas box that was attached to an exhaust system. This set-up facilitated removal of the odors from the box where the bees were trained. The bees were positioned in the box and allowed to adjust to the surroundings for $30 \mathrm{~s}$ before each trial began. The two odors used as the conditioned stimuli were kept in separate syringe barrels placed $1.5 \mathrm{~cm}$ from the head of the bee. In each training session, one conditioned stimulus $(\mathrm{CS}+)$ would be paired with an appetitive unconditioned stimulus (US + ) (sucrose) and the other conditioned stimulus (CS-) with an aversive US- (salt). The tip of the syringe, facing away from the bee, was fitted with tubing for the delivery of air through the barrel. An aquarium pump controlled by a computer provided airflow. Air containing the odor (either CS + or CS-) was blown through the syringe barrel and over the bee for $4 \mathrm{~s}$. Three seconds after the beginning of the odor exposure, the computer signaled for the presentation of the US. The appetitive US + $\left(0.4 \mu \mathrm{l}\right.$ of $2 \mathrm{~mol} \mathrm{l}^{-1}$ sucrose $)$ was presented to the bee after the CS + by first touching a drop of sucrose to the antenna and then to the proboscis for two seconds of feeding. The aversive US- $\left(0.4 \mu \mathrm{l}\right.$ of $\left.3 \mathrm{~mol} \mathrm{l}^{-1} \mathrm{NaCl}\right)$ was touched to the antenna of each bee, regardless of its response to the odor of the CS-. In most conditioning sessions, eight bees were trained at a time, four from the hygienic line and four from the non-hygienic line. There was an 8-min inter-trial interval for each bee. Conditioning sessions were repeated with new bees on successive days until the sample size was sufficient.

Bees were exposed to each odor in the pair for 8 trials, for a total of 16 trials in an experiment. In the first trial, the CS + was paired with the US + . In the second trial, the CS- was paired with the US-. Thereafter, the conditioned and unconditioned stimuli were presented in a pseudo-random sequence of the CS $+/ \mathrm{US}+$ and CS-/US-. Bees that extended their proboscises (spontaneous responders) to the presentation of the $\mathrm{CS}+$ in the first trial were excluded from the experiments because it could not be determined if their future responses to the $\mathrm{CS}+$ and $\mathrm{CS}$ - were a result of conditioning.

The odors used as the CS + and the CS- were live, healthy pupae and pupae infected with chalkbrood (mummies). Live, healthy pupae with light pink-purple eyes (Jay 1962) were removed from their capped cells carefully to prevent injury. White and black chalkbrood mummies (with and without fruiting bodies, respectively) were collected from a frame of brood and kept at room temperature in a covered Petri dish. The mummies and healthy pupae were placed into separate $12-\mathrm{ml}$ plastic syringe barrels. One or more live pupae or chalkbrood mummies were placed into the syringe through which air was passed. In the Age study, two healthy pupae and two chalkbrood mummies were used as the conditioned stimuli for each age group. This stimulus level was lower than the one used in our previous experiment (Masterman et al. 2000). In the threshold experiment, three stimulus levels were presented to the bees: a low stimulus level of one healthy pupa and one chalkbrood mummy, and two higher stimulus levels (two and four healthy pupae and chalkbrood mummies, in 1997, and two and eight in 1998). New syringes were used for each stimulus level.

\section{PER statistical analysis}

In the PER discrimination experiments, a positive response (proboscis extension) to the presentation of either the CS + or CS- was scored as 1, a negative response (no proboscis extension) was 
scored as 0 . The proportion of proboscis extension response to each odor over the 16 trials was plotted as learning curves. The relative differences between the asymptotes to the $\mathrm{CS}+$ and the CS- provides a visual estimation of the discrimination ability.

A discrimination index (DI) was used to analyze statistically the differences between the hygienic and non-hygienic bees' ability to discriminate between each odor pair. The discrimination index was calculated by subtracting the sum of the responses to the punished odor from the sum of the responses of the rewarded odor. A high positive index would indicate that the bees extended their proboscises to the rewarded odor, but withheld them for the punished odor. The results of the discrimination index could range from a high of seven (seven positive responses to the CS + and 0 positive responses to the $\mathrm{CS}-)$ to a low of -8 ( 0 positive responses to the $\mathrm{CS}+$ and eight positive responses to the $\mathrm{CS}-$-). The indices for each line were compared using Mann-Whitney $U$-tests.

The total number of times the bees extended their proboscises in an experiment was also analyzed. The total proboscis extension (TPE) responses to the CS + and CS- were added for each bee. The range of the total proboscis extension index could range from 0 to 15. A high total would indicate that the bees tended to extend their proboscises to both odors rather then withholding their proboscises to the punished odor. The TPE responses for the bees in each line were analyzed using Mann-Whitney $U$-tests.

\section{Electroantennogram methods}

The EAG experiments were conducted during the last week of August and 1st week of September 2000. For these experiments, three hygienic and three non-hygienic colonies were chosen from the 7th generation of selected colonies, all derived from different sublines. These colonies were maintained in small "nucleus" boxes, each containing three to four frames of brood and one to two frames of stored nectar and pollen. All bees developed in their respective colonies (they were not transferred to a nursery colony). Cohorts of 1-day-old bees were marked each day for 1 week with a unique color of non-toxic paint and were replaced into their respective colonies. After 2 weeks, marked bees between the ages of 15 days and 18 days (mean age 16.8 days) were selected randomly from their colonies for EAG studies. A freeze-killed brood stimulus was not introduced into the colony before collection of the bees to elicit hygienic behavior. These methods allowed us to establish the baseline thresholds of the bees, regardless of colony genotype composition or behavioral status at the time of collection.

\section{Electrophysiological recordings}

Recording electrodes consisted of glass microcapillary tubes containing chloride silver wire and physiological saline consisting of $\left(\mathrm{mmol} \mathrm{l}^{-1}\right)$ : $210 \mathrm{NaCl}, 3.1 \mathrm{KCl}, 10 \mathrm{CaCl}_{2}, 2.1 \mathrm{NaHCO}_{3}, 0.1$ $\mathrm{NaH}_{2} \mathrm{PO}_{4}$ (Patte et al. 1989). Bees were chilled until they became inactive and then placed into $1-\mathrm{ml}$ tapered pipette tips so that only the head protruded from the tapered end. The ground electrode was inserted into the haemolymph of the posterior head capsule. Insertion of the ground electrode into the head capsule limited movement of the head which resulted in more stable recordings. A small portion of the distal tip of the bee antenna was removed and the recording electrode was advanced into the opening until electrical continuity with ground was achieved. EAG responses were amplified and recorded using a Cornerstone IX2-700 intracellular d.c. pre-amplifier (Dagan, Minneapolis, Minn.) and a Maclab digital acquisition system using the Chart program.

A constant flow $\left(125 \mathrm{ml} \mathrm{min}^{-1}\right)$ of charcoal-filtered humidified air was passed continuously over the bee during recording sessions. Application of a constant, unvarying air-stream resulted in adaptation of antennal mechanoreceptors, which resulted in more reliable and repeatable measures of the summed antennal olfactory responses (Bhagavan and Smith 1997).

Experiments were performed at approximately $23^{\circ} \mathrm{C}$. Hexane (saturated vapor pressure, $\mathrm{SVP}=0.68$ ) was used as the control odorant at $1 / 23$ of SVP (370 ppm; Patte et al. 1989). Odorant preparations consisted of chalkbrood extract dissolved in hexane. One chalkbrood equivalent (CBE) was defined as one pupa dissolved in $2 \mathrm{ml}$ of control strength hexane. Subsequent dilutions were made by addition of hexane. A 5- $\mu$ l aliquot of odorant was placed onto a filter strip inserted into glass tubes. Tubes were sealed until use and discarded after each trial presentation. Odorants were presented to bees by shunting odorant into the constant air stream. For all presentations, the duration of stimulus delivery was $2 \mathrm{~s}$, and inter-stimulus intervals equaled 2 min. Order of presentation was as follows: control, 0.1 CBE, control, 0.5 CBE, control, $1 \mathrm{CBE}$, control, 2 CBE. Peak amplitude of the response was measured using Maclab software. Data were standardized by subtracting the response to hexane (control) from the response to each $\mathrm{CBE}$.

\section{EAG statistical analysis}

The effects of line (hygienic and non-hygienic) on the EAG response over varying concentrations were analyzed using a repeated, two-way ANOVA (Proc GLM, SAS Institute). A repeated-measures ANOVA was used because the same bees were tested over varying concentrations. Post-hoc comparison of the mean EAG responses between the two lines, at each concentration, was made using Tukey's HSD test. A Wilks-Shapiro Rankit plot was used to test for normality and Chi-square was used to test for equality of variance.

\section{Results}

\section{Age study}

If there was good odor discrimination, the bees would have high levels of response to the rewarded odors and low levels of response to the punished odors. Analysis of DIs (Table 1) indicated that 3-week-old hygienic bees discriminated between healthy and diseased brood odors significantly better than 3-week-old non-hygienic bees in the mixed-line composition colony when pupae was the $\mathrm{CS}+$ (Fig. 1B) and in the single-line colony when chalkbrood was the CS+ (Fig. 2D). There were no significant differences in DI between 1-week-old hygienic and non-hygienic bees whether in mixed- or single-line colonies. There also were no significant differences in DI between 1-week-old and 3-week-old bees within genetic lines. However, the non-hygienic bees had significantly higher TPE (Table 1) than hygienic bees at both 1 week and 3 weeks in both mixed- and single line colonies (Figs. 1, 2) with one exception (Fig. 2A, single-line colony at 1 week, when pupae was $\mathrm{CS}+$ ). The high TPE responses to both odors by the non-hygienic bees indicated that they generalized between the odors; they did not learn to discriminate by withholding their proboscises to the punished odors (whether CS- was chalkbrood or healthy pupae) as they aged. Thus, relative to the non-hygienic bees, the hygienic bees discriminated better between the odors overall.

\section{Threshold study}

For the Threshold study, in contrast to the Age study, a stimulus that triggers hygienic behavior was present in 
Table 1 Age study. Discrimination index (DI) median scores (ranges in parentheses) and total proboscis extension (TPE) median scores (and ranges) for the hygienic and non-hygienic bees within mixed-line and single-line composition colonies in 1998. Data from the mixed-line colonies when pupae were used as CS + corresponds with Fig. 1A, B, and when chalkbrood was CS + with Fig. 1C, D. Data from single-line colonies when pupae were CS + corresponds with Fig. 2A, B, and when chalkbrood was CS + with Fig. 2C, D ( $C S$ conditioned stimulus)

\begin{tabular}{|c|c|c|c|c|c|c|c|c|c|c|c|c|}
\hline & \multicolumn{6}{|l|}{ Mixed-line } & \multicolumn{6}{|l|}{ Single-line } \\
\hline & \multicolumn{3}{|l|}{ Pupae CS + } & \multicolumn{3}{|c|}{ Chalkbrood CS +} & \multicolumn{3}{|c|}{ Pupae CS + } & \multicolumn{3}{|c|}{ Chalkbrood CS +} \\
\hline & Hyg & & Non-H & Hyg & & Non-H & Hyg & & Non-H & Hyg & & Non-H \\
\hline \multicolumn{13}{|l|}{ DI } \\
\hline 1 week & $\begin{array}{l}1.0 \\
(-2.0-6.0)\end{array}$ & & $\begin{array}{l}0.0 \\
(-2.0-5.0)\end{array}$ & $\begin{array}{l}0.5 \\
(-2.0-6.0)\end{array}$ & & $\begin{array}{l}0.0 \\
(-3.0-5.0)\end{array}$ & $\begin{array}{l}0.0 \\
(-3.0-5.0)\end{array}$ & & $\begin{array}{l}1.0 \\
(-2.0-5.0)\end{array}$ & $\begin{array}{l}1.0 \\
(-3.0-5.0)\end{array}$ & & $\begin{array}{l}2.0 \\
(-3.0-6.0)\end{array}$ \\
\hline 3 weeks & $\begin{array}{l}2.0 \\
(-1.0-4.0)\end{array}$ & $* *$ & $\begin{array}{l}0.0 \\
(-3.0-6.0)\end{array}$ & $\begin{array}{l}1.0 \\
(-1.0-5.0)\end{array}$ & & $\begin{array}{l}0.50 \\
(-2.0-5.0)\end{array}$ & $\begin{array}{l}2.0 \\
(-3.0-5.0)\end{array}$ & & $\begin{array}{l}1.0 \\
(-2.0-6.0)\end{array}$ & $\begin{array}{l}1.0 \\
(-1.0-6.0)\end{array}$ & $*$ & $\begin{array}{l}0.0 \\
(-1.0-4.0)\end{array}$ \\
\hline \multicolumn{13}{|l|}{ TPE } \\
\hline 1 week & $\begin{array}{l}6.0 \\
(0-15.0)\end{array}$ & $*$ & $\begin{array}{l}11.0 \\
(0-15.0)\end{array}$ & $\begin{array}{l}5.5 \\
(0-14.0)\end{array}$ & $* *$ & $\begin{array}{l}11.0 \\
(2.0-15.0)\end{array}$ & $\begin{array}{l}6.0 \\
(0-15.0)\end{array}$ & & $\begin{array}{l}10.0 \\
(0-15.0)\end{array}$ & $\begin{array}{l}7.0 \\
(0-13.0)\end{array}$ & $*$ & $\begin{array}{l}10.0 \\
(0-14.0) \\
* *\end{array}$ \\
\hline 3 weeks & $\begin{array}{l}7.0 \\
(0-13.0)\end{array}$ & $*$ & $\begin{array}{l}11.0 \\
(0-15.0)\end{array}$ & $\begin{array}{l}3.0 \\
(0-15.0)\end{array}$ & $* *$ & $\begin{array}{l}10.0 \\
(0-15.0)\end{array}$ & $\begin{array}{l}6.0 \\
(1.0-15.0)\end{array}$ & $*$ & $\begin{array}{l}9.0 \\
(0-14.0)\end{array}$ & $\begin{array}{l}9.5 \\
(0-15.0)\end{array}$ & $* *$ & $\begin{array}{l}12.0 \\
(0-15.0)\end{array}$ \\
\hline
\end{tabular}

*Between two horizontal scores indicate significant differences in $* P \leq 0.05$;

DI or TPE between hygienic and non-hygienic bees within an age $* * P \leq 0.01$

class (Mann Whitney $U$-test)

*Between two vertical scores indicate significant different in DI or

TPE between age classes within genetic line of bees (Mann Whitney

$U$-test)

Fig. 1 Age study: single-line colonies. Percentage proboscis extension $(\% \mathrm{PE})$ over 16 trials ( 8 trials for each odor in a pair) by 1 -week and 3 -week-old hygienic (solid lines) and nonhygienic bees (dashed lines) in single line composition colonies, when pupae was $\mathrm{CS}+$ and chalkbrood was CS- (A, B), and when chalkbrood was CS + and pupae was $\mathrm{CS}-(\mathbf{C}, \mathbf{D})$. $C S$ conditioned stimulus. Sample sizes and mean ages $( \pm \mathrm{SD})$ :

A $\operatorname{Hyg} n=28,7.1 \pm 0.7$ days; Non-Hyg $n=29,7.2 \pm 0.9$ days; B $\operatorname{Hyg} n=22,22.8 \pm 1.5$ days; Non-Hyg $n=21$,

$22.5 \pm 1.7$ days; $\mathbf{C} \operatorname{Hyg} n=25$, $7.2 \pm 0.9$ days; Non-Hyg $n=21$, $7.0 \pm 0.9$ days; $\mathbf{D} H y g n=26$, $22.0 \pm 1.6$ days; Non-Hyg $n=24,22.0 \pm 1.7$ days

\section{Pupae CS+}

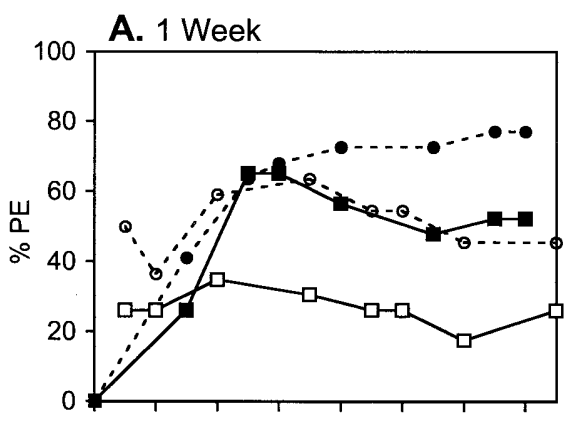

B. 3 Weeks

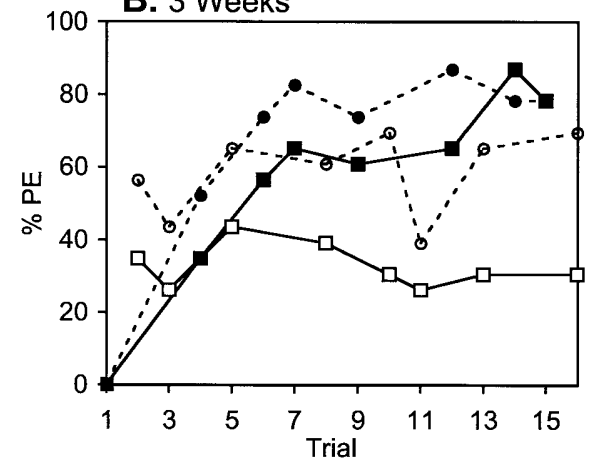

\section{Chalkbrood CS+}

C. 1 Week

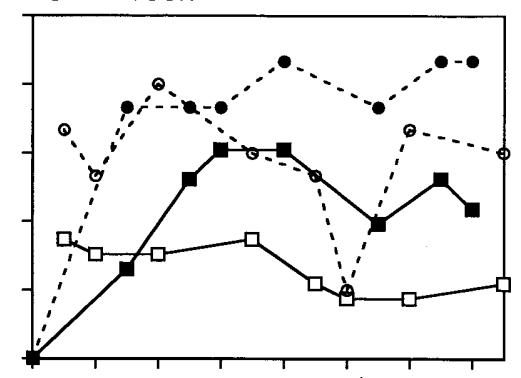

D. 3 Weeks

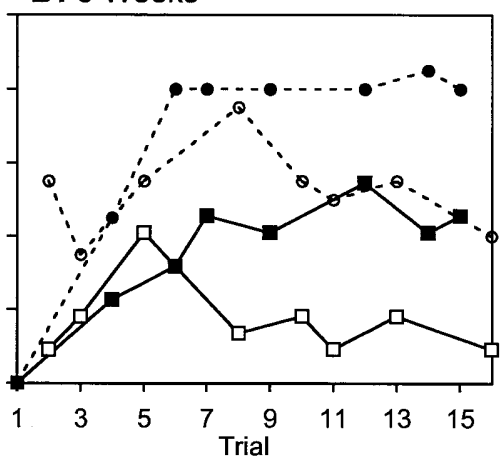

$\begin{array}{llll}\longrightarrow & \text { Hyg (CS+) } & --- & \text { Non-Hyg (CS+) } \\ \square & \text { Hyg (CS-) } & ---0--- & \text { Non-Hyg (CS-) }\end{array}$

the colonies. In both years and whether in mixed- or single-line composition colonies, the ability of both hygienic and non-hygienic bees to discriminate between the brood odors improved with increasing stimulus levels (Table 2; Figs. 3, 4). In all cases, the DI of hygienic bees increased significantly between the low and medium 
Fig. 2A-D Age study: mixedline colonies. Percentage proboscis extension (PE) over 16 trials ( 8 trials for each odor in a pair) by 1-week and 3-week-old hygienic (solid lines) and nonhygienic bees (dashed lines) in mixed line composition colonies when pupae was $\mathrm{CS}+$ and chalkbrood was CS- (A, B), and when chalkbrood was CS + and pupae was $\mathrm{CS}-(\mathbf{C}, \mathbf{D})$.

Sample sizes and mean ages $( \pm \mathrm{SD}): \mathbf{A} H y g n=23$,

$7.7 \pm 1.1$ days; Non-Hyg $n=22$, $7.7 \pm 0.8$ days. B Hyg $n=23$,

$21.7 \pm 0.7$ days; Non-hyg $n=23$, $21.4 \pm 0.7$ days. C Hyg $n=23$, $8.0 \pm 1.4$ days; Non-Hyg $n=15$, $8.0 \pm 1.5$ days. D Hyg $n=22$, $21.0 \pm 0.7$ days; Non-hyg $n=20$, $20.8 \pm 0.8$ days
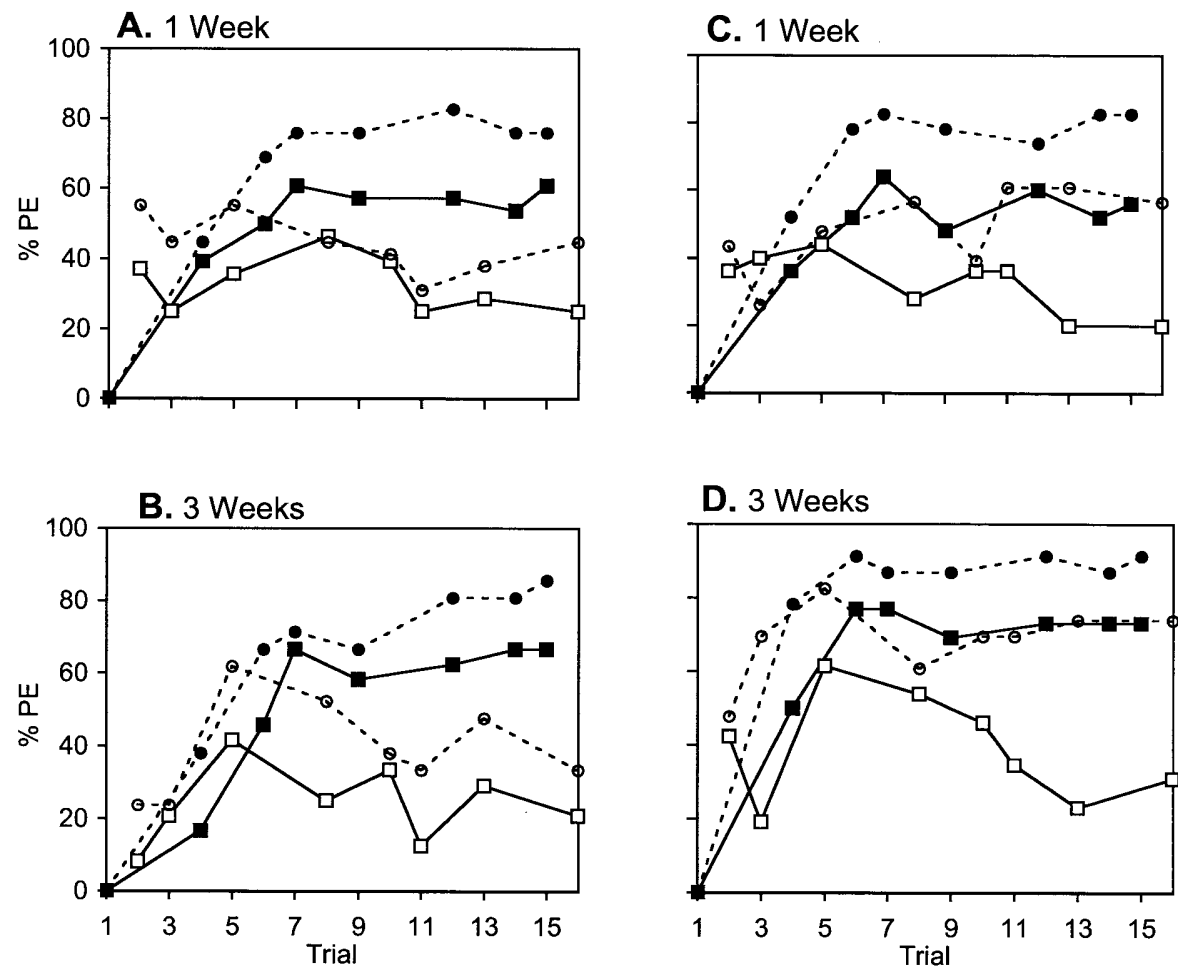

D. 3 Weeks

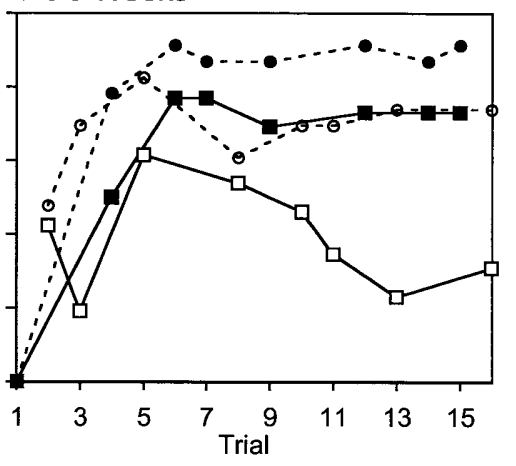

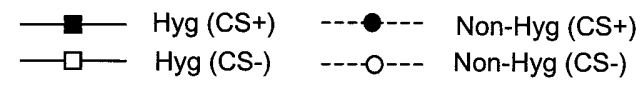

Table 2 Threshold study. DI median scores (ranges in parentheses) and TPE median scores (and ranges) for the hygienic and nonhygienic bees within mixed-line (1997) and single-line composition colonies (1998) at three stimulus levels. The low, medium and high stimulus levels were, respectively, 1, 2, and 4 (1997) and 1, 2, and 8
(1998) live pupae and chalkbrood mummies. Data from the mixedline colonies when pupae were used as $\mathrm{CS}+$ corresponds with Fig. 3A, B, C and when chalkbrood was CS + with Fig. 3D, E, F. Data from single-line colonies when pupae were $\mathrm{CS}+$ corresponds with Fig. 4A, B, C, and when chalkbrood was CS + with Fig. 4D, E, F

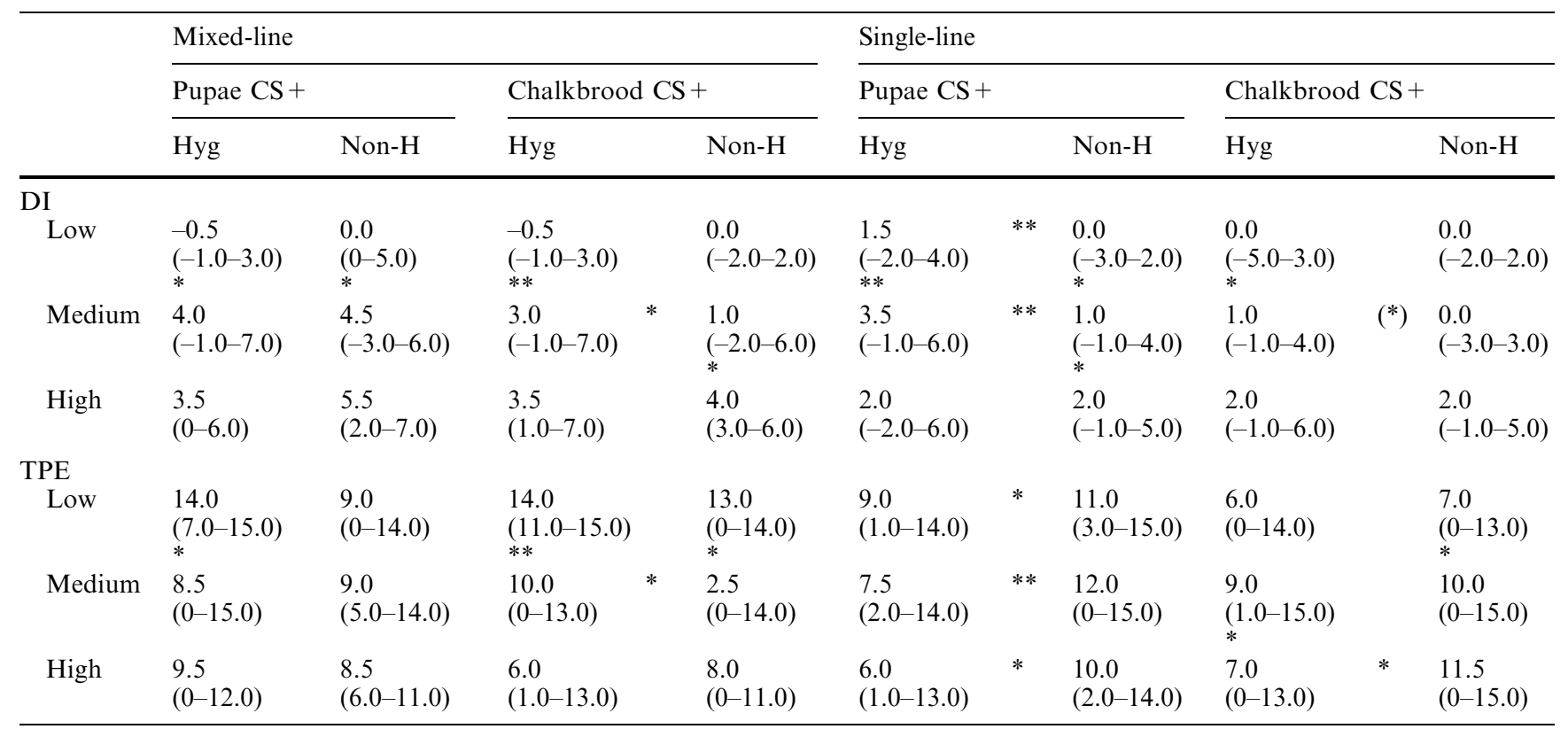

* Between two horizontal scores indicate significant differences in DI or TPE between hygienic and non-hygienic bees within a stimulus level (Mann Whitney $U$-test)

*Between two vertical scores indicate significant different in DI or

$* P \leq 0.05$

$* * P \leq 0.01$

TPE among two stimulus levels within genetic line of bees (Mann

$(*) P \leq 0.057$

Whitney $U$-test) 
Fig. 3A-F Threshold study: mixed-line composition colonies. Percent proboscis extension $(\% \mathrm{PE})$ over 16 trials $(8$ trials for each odor in a pair) by hygienic (solid lines) and nonhygienic (dashed lines) bees in mixed line composition colonies. A-C Live pupae odor was rewarded $(\mathrm{CS}+)$ and chalkbrood mummy odor was punished (CS-). D-F Brood odors reversed: chalkbrood mummy odor was CS + and live pupae odor was CS-. Low odor level was one chalkbrood mummy and one live pupae; medium level was two chalkbrood and two pupae; high level was four chalkbrood and four pupae. Sample sizes: A $H y g n=8$, Non-Hyg $n=7$; B Hyg $n=20$, Non-Hyg $n=17$; C Hyg $n=8$, Non-Hyg $n=8 ; \mathbf{D} H y g n=8$, Non-Hyg $n=7$; E Hyg $n=12$, Non-Hyg $n=13$; F Hyg $n=8$, Non-Hyg $n=7$
Pupae CS+
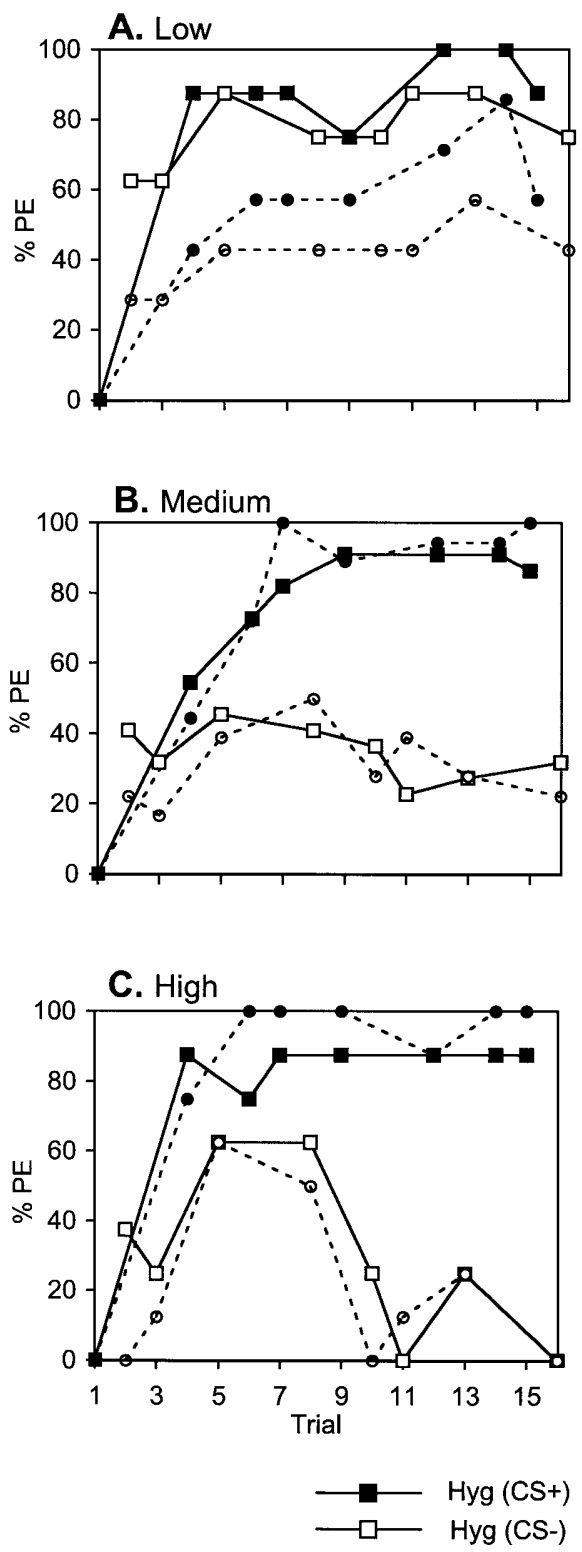

Chalkbrood CS+

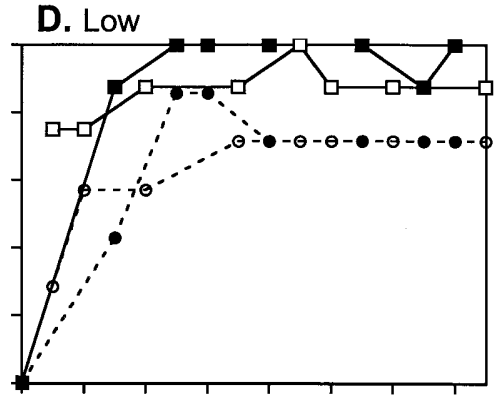

E. Medium

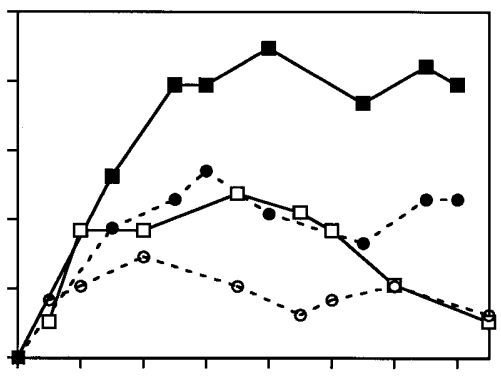

F. High

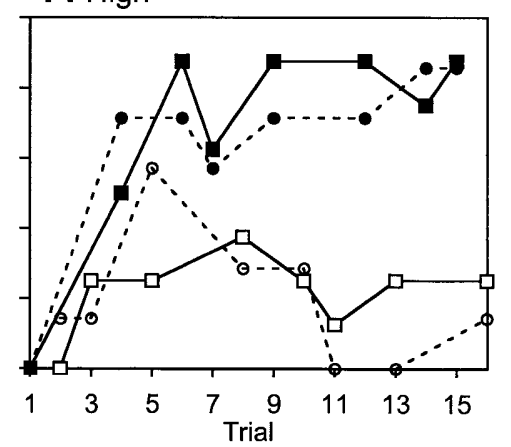

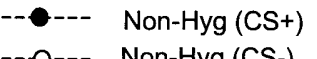

---O--- Non-Hyg (CS-)

stimulus levels, and did not increase significantly between the medium and high levels. In contrast, the DI of non-hygienic bees increased significantly only between the low and medium stimulus levels in the mixed-line colony when pupae was the CS + (Fig. 3A, B). In the other three cases, the DI of non-hygienic bees increased between each level (Fig. 4A-C), or between the medium to high levels (Figs. 3E, F, 4E, F; the latter not being statistically significant, $P=0.067$ ).

At the low stimulus level (Figs. 3A, D, 4A, D) hygienic and non-hygienic bees did not discriminate well between the brood odors, and there were no significant differences between the genetic lines of bees in DI or TPE, except in the single-line colony when pupae was the CS + (Fig. 4A, Table 2). At the high stimulus level (Figs. 3C, F, 4C, F) all bees discriminated relatively well between the odors regardless of which odor was the $\mathrm{CS}+$ and which odor was the CS-. There were no significant differences in DI between the genetic lines of bees at the high level, but the non-hygienic bees had significantly higher TPE scores in the single-line colony, indicating they were still tending to generalize between the odors (Table 2). At the intermediate stimulus level, the hygienic bees discriminated significantly better between the brood odors than the non-hygienic bees when the CS + was chalkbrood in the mixed-line composition colonies (Fig. 3E), and in the single-line composition colonies regardless of how the odors were paired (Fig. 4B, E).

Overall, the results show that hygienic bees were able to discriminate between healthy and diseased brood odors at a lower stimulus level than non-hygienic bees, 
Fig. 4A-F Threshold study: single-line composition colonies. Percent proboscis extension $(\% \mathrm{PE})$ over 16 trials $(8$ trials for each odor in a pair) by hygienic (solid lines) and nonhygienic (dashed lines) bees in single line composition colonies. A-C Live pupae odor was rewarded $(\mathrm{CS}+)$ and chalkbrood mummy odor was punished (CS-). D-F Brood odors reversed: chalkbrood mummy odor was CS + and live pupae odor was CS-. Low odor level was one chalkbrood mummy and one live pupae; medium level was two chalkbrood and two pupae; high level was eight chalkbrood and eight pupae. Sample sizes: A Hyg $n=18$, Non-Hyg $n=21$; B Hyg $n=32$, Non-Hyg $n=29 ;$ C Hyg $n=22$, Non-Hyg $n=17$; D Hyg $n=20$, Non-Hyg $n=18$; E Hyg $n=23$, Non-Hyg $n=23$; F Hyg $n=20$, Non-Hyg $n=18$
Pupae CS+
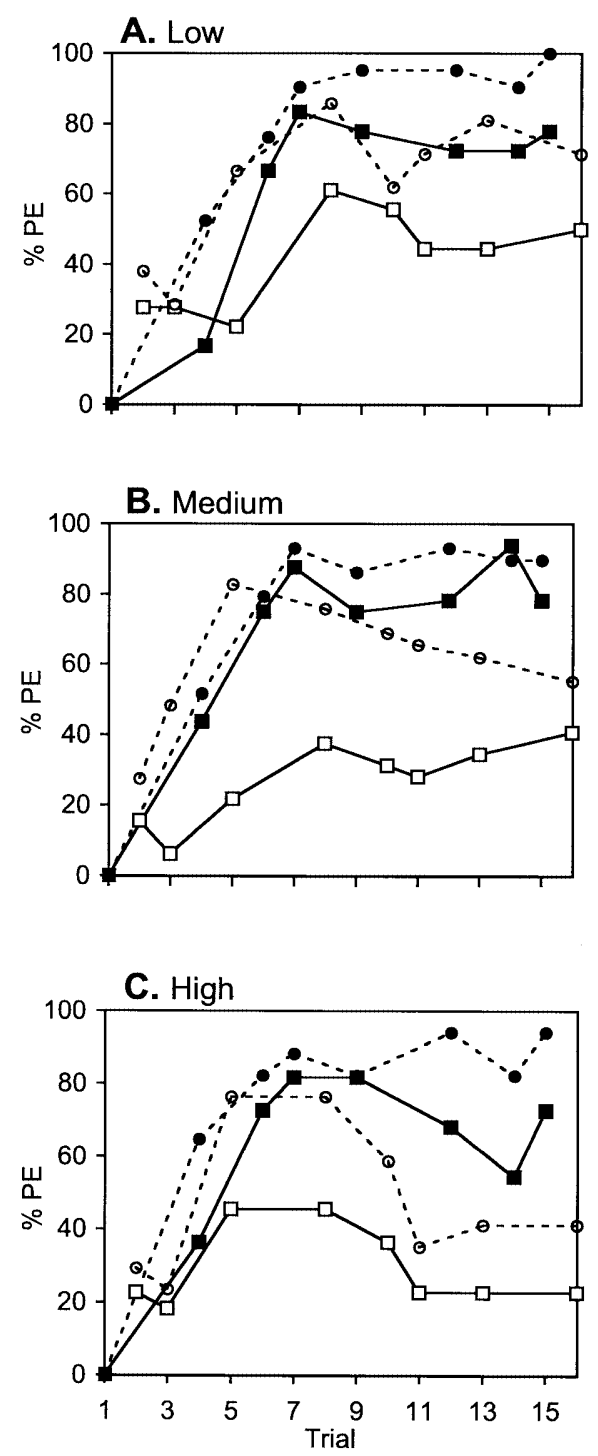

\section{Chalkbrood CS+}

D. Low

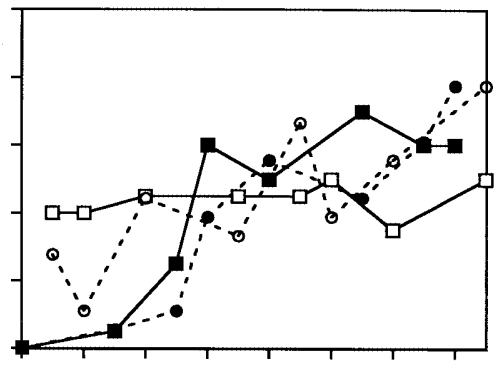

E. Medium

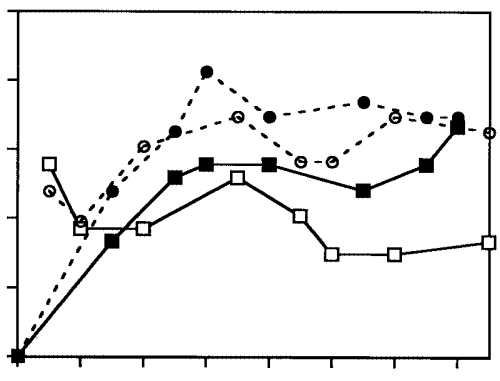

F. High

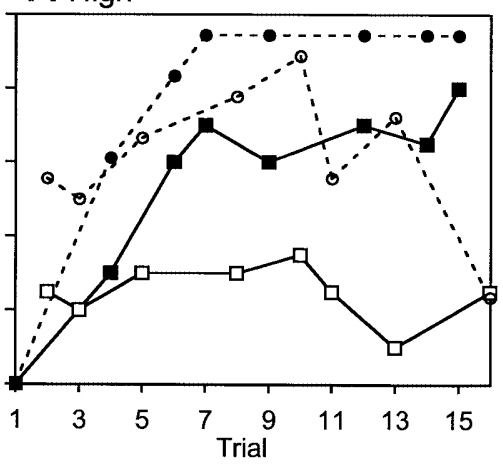

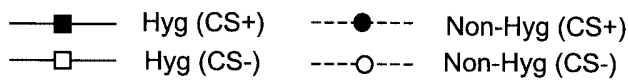

suggesting that hygienic bees have a lower behavioral response threshold to these odors.

\section{Asymmetrical responses to PER}

Asymmetrical responses were observed in the odor discrimination abilities in both studies. For example, in the Age study, hygienic bees in the mixed-line colony discriminated better between the brood odor pair when pupae was the $\mathrm{CS} \pm$ (Fig. 1B versus D). In the threshold study, asymmetrical responses were also observed (within non-hygienic bees in Fig. 3B versus E; and hygienic bees in Fig. 4C versus F). Asymmetrical responses suggest that the two odors were not equally salient to the bees (Bhagavan and Smith 1997).
EAG threshold responses to brood odors

Bees selected for hygienic behavior exhibited significantly increased sensitivity to chalkbrood odor at the lower stimulus concentrations $(0.1$ and $0.5 \mathrm{CBE})$ than bees selected for non-hygienic behavior (Fig. 5). The repeated two-way ANOVA demonstrated that the mean EAG responses of bees selected for hygienic behavior were significantly greater than those of non-hygienic bees $(F=76.14 ; d f=1,150 ; P<0.0001)$. There was no significant difference in responses within lines $(F=0.14$; $d f=2,150 ; P=0.866)$. Tukey's HSD test indicated significant differences between the lines at the two lower concentrations, 0.1 $\mathrm{CBE}$ and $0.5 \mathrm{CBE}$, but not at the higher concentrations of 1.0 CBE and 2.0 CBE. No significant differences were observed between the lines to 


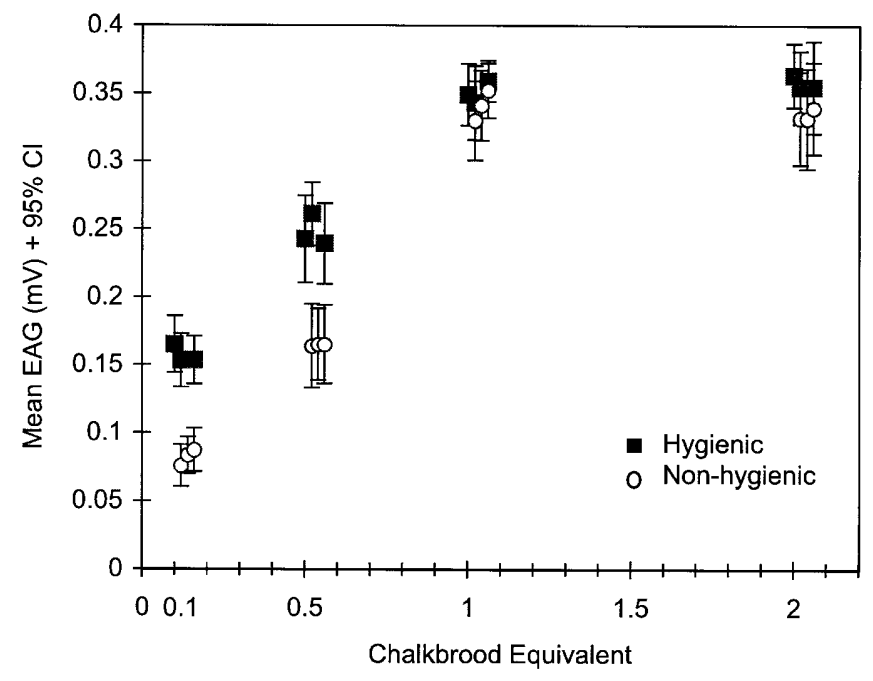

Fig. 5 The mean electroantennogram (EAG) response $(n=25$ bees per colony) and $95 \%$ confidence intervals for the three hygienic and three non-hygienic colonies. Bees selected for hygienic behavior exhibited significantly increased sensitivity to chalkbrood odor at the 0.1 and 0.5 chalkbrood equivalents (CBE). No significant differences were observed at the two higher concentrations of chalkbrood equivalents

the hexane control $(F=0.525, d f=5,150 ; \quad P=0.757)$ demonstrating that the hygienic bees did not exhibit increased olfactory sensitivity to both diseased brood and hexane odors.

\section{Discussion}

\section{PER Age study}

The results of the Age study show that three week old hygienic bees were able to discriminate between healthy and diseased brood odors significantly better than same aged non-hygienic bees. The non-hygienic bees tended to generalize between the brood odors at both 1 week and 3 weeks of age, and therefore did not discriminate as well. The results demonstrate that regardless of the bees' behavioral state at the time of collection, there were inherent differences in the way the two lines discriminated between brood odors. Thus, differential performance in brood odor discrimination is genetically based, not a result of the temporary behavioral state of the bee while uncapping brood cells or removing dead pupae.

Relatively low levels of discrimination (low DI scores) were observed at the stimulus level presented. The asymptotes of the proboscis extension responses of bees were unlike those obtained in studies in which bees were easily able to discriminate between odors if presented at high concentrations (Masterman et al. 2000). These odor levels were chosen because previous experiments demonstrated that it was more difficult for the bees from both lines to discriminate between them compared to a more salient odor, such as a larger number of pupae and mummies, or a floral odor such as geraniol (Masterman et al. 2000). A higher level of the brood odors would not have revealed variation in discrimination abilities.

Previous studies indicated that bees performing hygienic behavior are middle-aged bees, on average 15-17 $( \pm 6)$ days old (mean \pm SD) (Arathi et al. 2000). We evaluated the abilities of bees that were younger and slightly older than this age range to determine whether discrimination abilities changed with increased age, as would be expected if olfaction was involved with the performance of hygienic behavior. Such an increased ability to discriminate could be a result of exposure to hive odors or further development of the olfactory systems. Recent studies suggest that experience affects the performance of 10-day-old bees in single floral odor PER conditioning (Ray and Ferneyhough 1997). The ability to associate floral odor with reward increased to levels comparable to that of a mature forager in experienced 10-day-old bees, whereas inexperienced 10-dayold bees did not perform as well. Previous studies on the effect of age on the response to alarm pheromone in honey bees showed that initial response increased with the age of the bee after exposure to the pheromone in the laboratory (Collins 1981). However, in that experiment, young bees that emerged in an incubator were compared to 4-week-old bees, making it difficult to separate age from colony experience. The results from our study show that hygienic bees have only slight improvement in the ability to discriminate between brood odors as they age. Thus, the observed differences between hygienic and non-hygienic bees are inherent rather than a result of age and/or experience.

\section{PER and EAG response threshold studies}

The results of PER conditioning demonstrated that the ability of hygienic bees to discriminate between healthy and diseased brood odors increased significantly between the low and medium stimulus levels, whereas the ability of non-hygienic bees to discriminate increased more dramatically between the medium and high stimulus levels. In addition, hygienic bees trained at the intermediate stimulus level discriminated significantly better than the non-hygienic bees. These results provide supportive evidence for differential behavioral response thresholds between the two lines of bees. In turn, the EAG experiments demonstrated that hygienic bees, as compared to non-hygienic bees, possessed primary chemosensory neurons that exhibit increased sensitivity to the odor of chalkbrood at lower concentrations. We did not test if hygienic bees have increased sensitivity to all odors, but we did demonstrate that there was no significant difference between the sensitivity of hygienic and non-hygienic bees to the hexane control odor. Importantly, because the EAG studies were conducted on bees not collected in the act of performing hygienic behavior again we can rule out the possibility that this 'behavioral state' was primarily responsible for EAG 
response differences between the two lines. Our results strongly support the predictions of the 'response threshold model', which are that bees likely to perform specific behaviors have lower thresholds to stimuli that likely elicit the behavior.

\section{Differences in conditioned discrimination performance}

Previous studies have provided evidence for genetically based differences in PER conditioned discrimination performance (Bhagavan et al. 1994; Masterman et al. 2000). Bhagavan et al. (1994) described two lines of bees that were comprised of fast or slow learners in PER discrimination conditioning. The genetically based differences involved in slow and fast learning bees were determined to be a result of the inability of the slow learners to associate the CS and US (Benatar et al. 1995). Possibly, the poorer discrimination abilities of the non-hygienic bees may be related to a differential ability to detect the unconditioned stimuli (sucrose or salt). Thus, the difference in their abilities to associate the CS with the US may be based on the relative 'perceived' strength of the US. Studies using PER conditioning have shown that sensitivities to sucrose (the US, but not presented in conjunction with a CS) can vary by genotype (Page et al. 1998; Pankiw and Page 1999, 2000).

However, based on the EAG differences we obtained between the two lines, a more parsimonious explanation is that bees from the hygienic and non-hygienic lines possess different olfactory detection thresholds for the conditioned stimulus (chalkbrood odor). The lines of bees responded asymmetrically to the brood odor pair in PER conditioning, suggesting that the conditioned stimuli were not equally salient (Bhagavan and Smith 1997; Masterman et al. 2000). Because bees from the non-hygienic line were able to discriminate as well as bees from the hygienic line when the conditioned stimulus was presented at higher levels, these results support the idea that the non-hygienic bees are able to learn associations as well as the hygienic bees. We propose that the enhanced olfactory sensitivity of the hygienic bees increases the salience, or relevance of the CS, and thus allows them to associate the CS at lower concentrations with the US more readily (Rescorla 1967).

Possible mechanisms contributing to enhanced detection of diseased brood

Results from these studies confirm for the first time the existence of a genetic predisposition for the enhanced detection of diseased brood odor in hygienic honey bees. Although such confirmation recognizes that differences in conditioned PER discrimination abilities may exist, these differences are likely a reflection of differences in the responses of primary sensory neurons to abnormal brood odors.
We have yet to determine the physiological bases underlying the neuronal threshold differences, as measured by EAG recording, between the two lines of bees. Because the EAG response is a measure of summed potentials among numerous types of antennal chemosensory neurons, we do not yet know if the hygienic bees possess a greater number of sensory neurons 'tuned' to odors of diseased brood, or whether similar types and numbers of neurons vary at the level of differences in sensory transduction. Although our preliminary scanning electron microscope study indicates that the two lines do not possess antennae that differ significantly in sensillar morphology or distribution, such cuticular structures could be differentially innervated. Alternatively, we may find that the two lines of bees possess a peripheral chemosensory system that is indistinguishable from the other, but differentially modulated by internal or external factors. In social insects, possible nest-related odors have been shown to alter the sensitivity of primary chemosensory neurons (Ziesmann 1996). In addition, the presence of neuromodulators may be involved in regulating olfactory sensitivity. Modulatory effects of the biogenic amines, such as serotonin, octopamine and dopamine, have been demonstrated to act on both central and peripheral neurons involved in olfaction and vision to effectively shape sensory responsiveness (Erber et al. 1993; Kloppenburg and Erber 1995; Battelle et al. 1999; Vargas and Lucero 1999). In particular, the neuromodulatory effect of octopamine has been demonstrated to confer increased olfactory sensitivity in a variety of invertebrates (Bicker and Menzel 1989; Roeder 1999). Our preliminary studies indicate that octopamine-immunoreactive neurons in the brains of hygienic and non-hygienic honey bees can vary depending on the 'hygienic' behavioral state of the bee (Masterman et al. 1997). Such flexibility may enable honey bees to regulate their sensitivities to diseased brood odors depending on the conditions of the hive; the particular neurohormonal state of hygienic bees may be one that enables them to detect odors of diseased brood more readily.

\section{Implications for colony-level behaviors}

Prior evidence for behavioral response thresholds in honey bees is based in part on studies of stinging behavior. Groups of honey bee workers display quicker, longer-lasting, and stronger reactions to increasing concentrations of isopentyl acetate, a component of the alarm pheromone associated with the sting (Collins and Rothenbuhler 1978). The pheromone-induced response increases as bees age (Collins and Rothenbuhler 1978; Paxton et al. 1994), and with increasing temperature and humidity (Collins 1981). Numerous studies have demonstrated response threshold differences among genetic lines of bees for tendency to sting. These differences were noted at the colony level (Stort 1976); in small groups of bees (Boch and Rothenbuhler 1974; Collins et al. 1987) among individual bees (Kolmes and Fergusson-Kolmes 
1989); and among cross-fostered bees (Paxton et al. 1994). In these studies, it was hypothesized that the behavior was mediated by the low response threshold of the bees receiving the pheromone signal, rather than from increased production of alarm pheromone by the bee producing it (Boch and Rothenbuhler 1974; Collins et al. 1980).

More recent studies link response threshold differences to the division of labor and colony-level phenotypes. Individual bees within an age cohort have genotypically different threshold sensitivities to sucrose concentrations that elicit the PER when sucrose is applied to the antennae (Page et al. 1998). The threshold PER of a pre-foraging-age worker bee to a particular sucrose concentration was found to be predictive of her preference for pollen, nectar or water foraging as an adult (Pankiw and Page 1999, 2000). Young bees that have a low PER response threshold for sucrose tend to collect water or pollen as adults; whereas, bees that have high PER response threshold for sucrose as pre-foragers tend to collect nectar loads of high concentration or return empty when they reach foraging age (Pankiw and Page 1999, 2000). Thus, inherent differences in response thresholds among individual bees can result in a division of labor among tasks associated with foraging.

The lower response thresholds of hygienic bees to stimuli associated with diseased brood, in combination with our ethological studies of individual hygienic and non-hygienic bees (Arathi et al. 2000; Arathi and Spivak 2001) demonstrate how response thresholds that operate at the level of the individual bee could comprise a colony-level behavioral phenotype. Hygienic bees are more likely to detect a low level of diseased brood, and successfully discriminate between the odors of healthy and diseased brood. In the colony, the detection of the odor stimulus would trigger bees with the lowest detection and response thresholds to begin uncapping and removing the diseased brood rapidly from the nest. It is possible that even among hygienic bees, those with the lowest response thresholds uncap diseased brood and those with slightly higher thresholds both uncap and remove the brood. This organization would account for our observed behavioral classifications of bees into those that perform a high frequency of uncapping and ones that perform both uncapping and removal behaviors to similar extents (Arathi and Spivak 2001). Non-hygienic bees require a high stimulus concentration to detect diseased brood in the colony, and are not able to discriminate diseased brood from a healthy brood unless the stimulus levels are high. Thus, in the colony, bees with the highest detection and response thresholds would not respond by uncapping and removing diseased brood unless the level of disease was very high. This situation would occur if there were no or few bees with low thresholds (hygienic bees) in the colony. Non-hygienic bees perform uncapping and removal behaviors, although at very low rates and with low efficiency (Arathi and Spivak 2001).
It is postulated that variable response thresholds to specific task-associated stimuli can result in altered probabilities of individuals engaging in a given task (Page 1997). Our study provides a sensory and behavioral example of how the complex colony-level expression of hygienic behavior may be influenced by the variable response thresholds of individual workers to stimuli that elicit the performance of the task.

Acknowledgements The authors thank Gary Reuter for his expert technical assistance with the honey bee colonies, Jackie Gaustad and Jenny Warner for assistance with PER conditioning, and H.S Arathi and the anonymous reviewers for their thoughtful review of the manuscript. The authors also thank David Tronrud, Jenny Warner, and John Hickey for assistance in the experiments and honey bee colony maintenance. This work is in partial fulfillment of the Ph.D. degree for R.M. at the University of Minnesota. We acknowledge the Louise T. Dosdall Fellowship, Alexander P. and Lydia Anderson Fellowship and University of Minnesota Department of Entomology Fellowships for support of R.M. This work was funded by grant number IBN 9722416 of the National Science Foundation awarded to M.S.

\section{References}

Anderson D, Trueman JWH (2000) Varroa jacobsoni (Acari: Varroidae) is more than one species. Exp Appl Acarol 24:165-189

Arathi HS, Spivak M (2001) Influence of colony genotypic composition on the performance of hygienic behaviour in the honey bee (Apis mellifera L.). Anim Behav (in press)

Arathi HS, Burns I, Spivak M (2000) Ethology of hygienic behaviour in the honey bee Apis mellifera L. (Hymenoptera: Apidae): behavioral repertoire of hygienic bees. Ethology 106:365379

Batelle BA, Calman BG, Hart MK (1999) Cellular distributions and functions of histamine, octopamine, and serotonin in the peripheral visual system, brain, and circumesophaeal ring of the horseshoe crab Limulus polyphemus. Microsc Res Tech 44: $70-80$

Benatar S, Cobey S, Smith BH (1995) Selection on a haploid genotype for discrimination learning performance: correlation between drone honey bees (Apis mellifera) and their worker progeny (Hymenoptera: Apidae) J Insect Behav 8:637-652

Bhagavan S, Smith BH (1997) Olfactory conditioning in the honey bee, Apis mellifera: effects of CS intensity. Physiol Behav 61:107-117

Bhagavan S, Benatar S, Cobey S, Smith BH (1994) Effect of genotype but not of age or caste on olfactory learning performance in the honey bee, Apis mellifera. Anim Behav 48: $1357-1369$

Bicker G, Menzel R (1989) Chemical codes for the control of behaviour in arthropods. Nature (Lond) 337:33-39

Blom J van der (1993) Individual differentiation in behaviour of honey bee workers (Apis mellifera L.). Ins Sociaux 40:345-361

Boch R, Rothenbuhler WD (1974) Defensive behaviour and production of alarm pheromone in honeybees. J Apic Res 13: 217-221

Boecking O, Drescher W (1991) Response of Apis mellifera L. colonies to brood infested with Varroa jacobsoni Oud. Apidologie 22:237-241

Boecking O, Drescher W (1992) The removal response of Apis mellifera L. colonies to brood in wax and plastic cells after artificial and natural infestation with Varroa jacobsoni Oud. and to freeze-killed brood. Exp Appl Acarol 16:321-329

Calderone NW, Page RE Jr (1988) Genotypic variability in age polyethism and task specialization in the honey bees, Apis mellifera (Hymenoptera: Apidae). Behav Ecol Sociobiol 22:17-25 
Calderone NW, Page RE Jr (1991) Evolutionary genetics of division of labor in colonies of the honey bee (Apis mellifera). Am Nat 138:69-92

Calderone NW, Page RE Jr (1992) Effects of interactions among genotypically diverse nest mates on task specialization by foraging honey bees (Apis mellifera). Behav Ecol Sociobiol 30:219-226

Collins AM (1981) Effects of temperature and humidity on honeybee response to alarm pheromones. J Apic Res 20:13-18

Collins AM, Rothenbuhler WC (1978) Laboratory test of the response to an alarm chemical, isopentyl acetate, by Apis mellifera . Ann Entomol Soc Am 71:906-909

Collins AM, Rinderer TE, Tucker KW, Silvester HA, Lackett JJ (1980) A model of honeybee defensive behavior. J Apic Res 19:224-231

Collins AM, Rinderer TE, Tucker KW, Pesante DG (1987) Response to alarm pheromone by European and Africanized honeybees. J Apic Res 26:217-223

De Jong R, Pham-Delegue MH (1991) Electroantennogram responses related to olfactory conditioning in the honey bee (Apis mellifera ligustica). J Insect Physiol 37:319-324

Erber J, Kloppenburg P, Scheidler A (1993) Neuromodulation by serotonin and octopamine in the honeybee- behaviour, neuroanatomy and electrophysiology Experientia 49:1073-1083

Gilliam M, Taber S III, Richardson GV (1983) Hygienic behavior of honey bees in relation to chalkbrood disease. Apidologie $14: 29-39$

Jay SC (1962) Colour changes in honeybee pupae. Bee World 43:119-122

Kloppenburg P, Erber J (1995) The modulatory effects of serotonin and octopamine in the visual system of the honey bee (Apis mellifera L.). II. Electrophysiological analysis of motion-sensitive neurons in the lobula. J Comp Physiol A 176:119-129

Kolmes SA, Fergusson-Kolmes LA (1989) Measurements of stinging behaviour in individual worker honeybees (Apis mellifera L.). J Apic Res 28:71-78

Masterman R, Spivak M, Reuter G, Klukas K, Mesce K (1997) Hygienic behavior and octopamine immunoreactive cells in the honey bee brain. Soc Neurosci Abstr 27:1336

Masterman R, Smith BH, Spivak M (2000) Brood odor discrimination abilities in hygienic and non-hygienic honey bees (Apis mellifera L.) using proboscis extension reflex conditioning. J Insect Behav 13:89-101

Menzel R, Bitterman ME (1983) Learning by honey bees in an unnatural situation. In: Huber F, Markl H (eds) Neuroethology and behavioral physiology. Springer, Berlin Heidelberg New York, pp 206-215

Page RE (1997) The evolution of insect societies. Endeavour $21: 114-120$

Page RE Jr, Mitchell SD (1991) Self-organization and adaptation in social insects In: Fine A, Forbes M, Wessels L (eds) PSA 1990, vol 2. Philosophy of Science Association, East Lansing, Michigan, pp 289-298

Page RE, Robinson GE (1991) The genetics of division of labour in honey bee colonies. Adv Insect Physiol 23:117-169

Page RE, Erber J, Fondrk MK (1998) The effect of genotype on response thresholds to sucrose and foraging behavior of honey bees (Apis mellifera L.). J Comp Physiol A 182:489-500

Pankiw T, Page RE Jr (1999) The effect of genotype, age, sex, and caste on response thresholds to sucrose and foraging behavior of honey bees (Apis mellifera L.) J Comp Physiol A 185: 207-213

Pankiw T, Page RE Jr (2000) Response thresholds to sucrose predict foraging division of labor in honeybees. Behav Ecol Sociobiol 47:265-267
Patte F, Etcheto M, Marfaing P, Laffort P (1989) Electroantennogram stimulus-response curves for 59 odorants in the honey bee, Apis mellifica. J Insect Physiol A 35:667-675

Paxton RJ, Sakamoto CH, Rugiga FCN (1994) Modification of honey bees (Apis mellifera L.) stinging behaviour by withincolony environment and age. J Apic Res 33:75-82

Peng YS, Fang Y, Xu S, Ge L, Nasr ME (1987) Response of foster Asian honey bee (Apis cerana Fabr.) colonies to the brood of European honey bee (Apis mellifera L.) infested with parasitic mite Varroa jacobsoni Oudemanns. J Invert Pathol 49:259-264

Ray S, Ferneyhough B (1997) The effects of age on olfactory learning and memory in the honey bee Apis mellifera. Neuroreport 8:789-793

Rescorla RA (1967) Pavlovian conditioning and its proper control procedures. Psychol Rev 74:71-80

Robinson GE (1992) Regulation of division of labor in insect colonies. Annu Rev Entomol 37:637-665

Roeder T (1999) Octopamine in invertebrates. Prog Neurobiol 59:533-561

Rothenbuhler WC (1964) Behaviour genetics of nest cleaning in honey bees. IV. Responses of F1 and backcross generations to disease-killed brood. Am Zool 4:111-123

SAS Institute (1989) SAS/STAT* User's Guide, version 6, 4th edn, vols 1 and 2. SAS Institute, Cary, NC

Seeley TD (1985) Honey bee ecology. Princeton University Press, Princeton, NJ

Seeley TD, Kolmes SA (1991) Age polyethism for hive duties in honey bees - illusion or reality? Ethology 87:284-297

Spivak M (1996) Honey bee hygienic behavior and defense against Varroa jacobsoni. Apidologie 27:245-260

Spivak M, Downey D (1998) Field assays for hygienic behavior in honey bees (Apidae: Hymenoptera). J Econ Entomol 91:64-70

Spivak M, Gilliam M (1998a) Hygienic behaviour of honey bees and its application for control of brood diseases and varroa. Part I. Hygienic behaviour and resistance to American foulbrood. Bee World 79:124-134

Spivak M, Gilliam M (1998b) Hygienic behaviour of honey bees and its application for control of brood diseases and varroa. Part II. Studies on hygienic behaviour since the Rothenbuhler era. Bee World 79:169-186

Spivak M, Reuter GS (1998) Performance of hygienic colonies in a commercial apiary. Apidologie 29:291-302

Spivak M, Reuter GS (2001) Varroa destructor infestation in untreated honey bee (Hymenoptera: Apidae) colonies selected for hygienic behavior. J Econ Entomol 94:326-331

Stort AC (1976) Genetic study of the aggressiveness of two subspecies of Apis mellifera in Brazil. III. Time taken for the colony to become aggressive. Cien Cult S Paulo 28:1182-1185

Theraulaz G, Bonabeau E. Deneubourg JL (1998) Response threshold reinforcement and division of labour in insect societies. Proc R Soc Lond Ser B 265:327-332

Vargas G, Lucero MT (1999) Dopamine modulates inwardly rectifying hyperpolarization-activated current (I-h) in cultured rat olfactory receptor neurons. J. Neurophysiol 81:149-158

Williams IH, Pickett JA, Martin AP (1982) Nasonov pheromone of the honeybee. Apis mellifera L. (Hymenoptera: Apidae). IV. Comparative electroantennogram responses. J Chem Ecol 8:567-574

Winston ML (1987) The biology of the honey bee. Harvard University Press, Cambridge, MA

Woodrow AW, Holst EC (1942) The mechanism of colony resistance to American foulbrood. J Econ Entomol 35:327-330

Ziesmann J (1996) The physiology of olfactory sensillum of the termite Schedorhinotermes lamanianus - carbon dioxide as a modulator of olfactory sensitivity. J Comp Physiol A 179:123-133 